\title{
Cardiac Surgery of Eight Children with Kawasaki Disease (Mucocutaneous Lymph Node Syndrome)
}

Kozo Suma, M.D., Yasuo Takeuchi, M.D., Kenji Shiroma, M.D., Takayuki Tsuji, M.D., Kenji Inove, M.D., Tetsuo Yoshikawa, M.D., Yuji Koyama, M.D. Jun Narumi, M.D., Toshio Asai, M.D., * and Sanji Kusakawa, M.D.*

\section{SUMmary}

The coronary arterial lesions of Kawasaki disease are characterized by multiple stenoses and aneurysms, which might lead to myocardial ischemia, myocardial infarction, mitral insufficiency due to ischemic papillary muscle dysfunction, ventricular aneurysm, etc.

Eight children aged 6 to 13 years with Kawasaki disease underwent surgical treatments. These were coronary bypass surgery, coronary bypass surgery combined with right coronary aneurysmectomy and coronary bypass surgery combined with left ventricular aneurysmectomy. The postoperative course was smooth in all the patients. The selective angiography performed 1 month after the operation revealed the patency rate of $85 \%$ of the bypass grafts. However, 1 patient died suddenly during strenuous exercise 3 years after the surgery.

Several points to be considered in the aortocoronary bypass in the patients with Kawasaki disease are discussed. These include the unknown fate of saphenous vein grafts and the possibility of higher incidences of graft failure in the growing children. Since the long-term postoperative results are as yet not fully understood, close follw-up of the patients treated by aortocoronary bypass surgery would be mandatory.

\section{Additional Indexing Words:}

Aortocoronary bypass aneurysmectomy

Autogenous saphenous vein Coronary Myocardial infarction Coronary aneurysm Thrombus formation Turbulent blood stream Ventricular aneurysmectomy

QINCE Kawasaki's report in $1967^{11}$ on a new clinical entity named muco1 cutaneous lymph node syndrome (MCLS), increasing number of the cases have been reported in Japan. ${ }^{2)}$ The symptoms of the disease are acute febrile conditions associated with hyperemia of the ocular conjunctiva, reddening of lips and oral and pharyngeal mucosa, indurative erythema of palms and soles, polymorphous exanthema on the trunk, swelling of the cervical lymph nodes,

From the Department of Cardiovascular Surgery and the Department of Pediatrics, * Tokyo Women's Medical College Hospital, 2-1-10 Nishi-Ogu, Arakawa-ku, Tokyo 116, Japan.

Received for publication August 11, 1980. 
etc. ${ }^{3)}$ In some cases, myocarditis is a concomitant symptom in acute stage, leading to heart failure. The patients are mostly infants and young children under 5 years of age. Initially, the prognosis was considered to be favorable, but recent reports about sudden death of the affected children after recovery from acute illness have drawn the profound attention of pediatricians to the sequelae of the disease in the cardiovascular, especially the coronary arterial system. ${ }^{4}$ The postmortem examinations showed that the coronary arteries were involved in acute stage in the form of panarteritis, leading to stenosis and aneurysmal dilatation of the coronary arteries at a later stage and that thrombus formation and/or morphological changes of the artery were the cause of myocardial ischemia resulting in sudden death. ${ }^{3)}$ In recent years surgery has been proposed as one of the treatments in some cases.51-81,16) We have treated surgically 8 cases with myocardial ischemia, which is the basis of this report.

\section{Case Reports}

\section{Case 1}

A 7-year-old boy developed MCLS with the symptom of heart failure 5 months after his birth. At the age of 5 , although free of symptoms, he was admitted to the hospital for the cardiovascular examination. ECG was compatible with myocardial infarction. Aortography revealed aneurysms at the origins of both the left and the right coronary arteries. Thereafter he was treated with daily administration of warfarin. At the age of 7 he underwent selective coronary angiography. It revealed an aneurysm at the left main trunk as well as 50\% narrowing of the lumen of the proximal anterior descending artery (LAD) and that of the proximal circumflex artery (CX). At the proximal half of the right coronary artery ( $R \mathrm{C})$, multiple aneurysmal dilatations and 50 to $90 \%$ stenoses were found. Good filling was observed in the distal right coronary artery.

Operation was performed on October 15, 1976. An aneurysm, about 1.5x $1.0 \mathrm{~cm}$ in size, was found at the origin of the left coronary artery. Scattered fibrotic regions were observed over the left ventricular lateral wall. The proximal right coronary artery appeared beads-like strand. Autogenous saphenous vein grafts were inserted from the aorta to the LAD and the RG. The distal anastomoses were performed with interrupted $7-0$ silk sutures. The flow to the $L A D$ was $20 \mathrm{ml} / \mathrm{min}$ and to the RC $30 \mathrm{ml} / \mathrm{min}$. The postoperative course was uneventful. Angiography performed 1 month after the surgery showed both grafts to be patent. The patient is now in good condition, enjoying normal school life.

\section{Case 2}

A 9-year-old girl had a history of MCLS at the age of 2. Six years later she began to develop episodes of syncopal attack. Chest X-ray showed calcification at the site of aortic root. ST segment depressions in leads II, III, aVF, and V4-6 were observed after exercise. Selective angiogram showed occlusion of the left coronary artery and 75 and $50 \%$ stenoses at the proximal right coronary artery. Good fil- 
ling was observed in the distal right coronary artery. The anterior descending and the circumflex artery were opacified retrogradely from the right coronary artery.

Operation was performed on December 22, 1976. A calcified aneurysm, about $1.5 \times 1.5 \mathrm{~cm}$ in size, was observed at the origin of the left coronary artery and an aneurysm, about $0.5 \times 0.5 \mathrm{~cm}$ in size, at the proximal right coronary artery. Graftings using autogenous saphenous veins were performed to the $\mathrm{CX}$ and to the RC. The anterior descending artery was too small for grafting. The flow through the graft to the $\mathrm{CX}$ was $5 \mathrm{ml} / \mathrm{min}$ and that to the $\mathrm{RC}$ was $50 \mathrm{ml} / \mathrm{min}$. Convalescence was uneventful. Angiography performed 1 month after the surgery revealed the graft to the $\mathrm{RC}$ to be patent, but that to the $\mathrm{CX}$ to be occluded. The patient was free of any symptom until 3 years after the surgery when she died suddenly during relatively strenuous exercise. The postmortem examinations revealed the graft to the $\mathrm{RC}$ to be patent, although marked intimal fibrous prolifcration in the grafted vein was observed.

\section{Case 3}

A 9-year-old boy had a history of MCLS at the age of 5. Two years later he was referred to our hospital for the evaluation of cardiovascular sequelae. EGG showed incomplete right bundle branch block with negative $\mathrm{T}$ wave in precordial leads. After exercise ST segments were depressed in leads II, III, and aVF. Coronary angiogram revealed an aneurysm at the proximal anterior descending artery and occlusion beyond the branching of the second diagonal. The first and the second diagonal branches had luminal narrowing of $75 \%$ and $90 \%$ respectively. Two aneurysms in series at the proximal circumflex artery as well as 50 and $90 \%$ stenoses in series in its major lateral branch were observed. The right coronary angiogram showed occlusion beyond the branching of the conus artery. The distal right coronary artery was opacified through the collaterals of the left coronary artery.

Operation was performed on November 16, 1977. An aneurysm, sized about $1.0 \times 3.0 \mathrm{~cm}$, was observed at the origin of the anterior descending artery and another aneurysm, sized about $2.0 \times 0.5 \mathrm{~cm}$, at the proximal circumflex artery. Both aneurysms, white and firm, were calcified. An arteriotomy of the anterior descending artery $3.0 \mathrm{~cm}$ distal to the aneurysm indicated the artery to be patent. An autogenous saphenous vein graft was anastomosed to the LAD with interrupted 7-0 silk sutures. Attempt was made to anastomose a graft to the $\mathrm{RC}$, but the artery was too small for grafting. Measurement of flow showed $40 \mathrm{ml} / \mathrm{min}$ through the graft, which was proved to be patent by the arteriography performed one month after the surgery. The patient is now enjoying normal school life.

Case 4

A 6-year-old girl had a history of MCLS with cardiac failure at the age of 8 months. Two years later she was referred to our hospital for the evaluation of cardiovascular sequelae. The chest X-ray showed calcification at the aortic root. $\mathrm{ECG}$ showed $\mathrm{q}$ wave at leads II, III, and aVF. Aortogram revealed aneurysms at both the proximal right and the left coronary arteries. Two years later selective coronary arteriography was performed, which showed an aneurysm at the bifurcation of the left coronary artery without any narrowing distal to the aneurysm and 2 large aneurysms in series at the proximal right coronary artery. Inside the aneurysms turbulent blood strcam was seen forming vortex. In addition $75 \%$ and $25 \%$ 
narrowings of the lumen were observed at the inlet and the outlet of the right coronary aneurysms, respectively.

Because of the increase in size of the right coronary aneurysms and the possibility of thrombus formation inside the aneurysms and peripheral embolization,

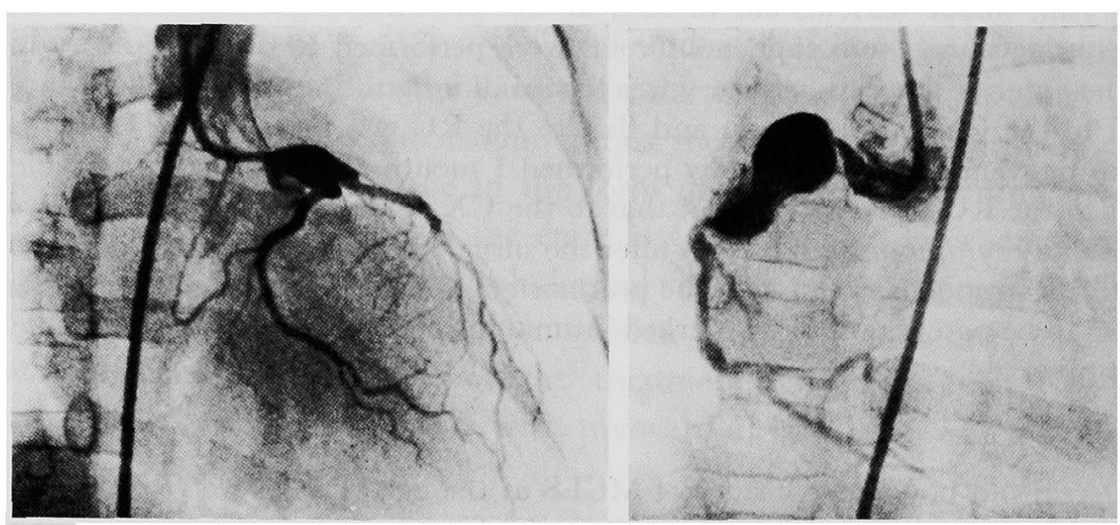

Fig. 1. Left: The left coronary angiogram in Case 4 shows an aneurysm at the bifurcation of the left artery. Right: The right coronary angiogram of the same patient shows 2 large aneurysms in series at the proximal right coronary artery. Coronary arterial stenoses can be seen at the inlet and the outlet of the aneurysms.

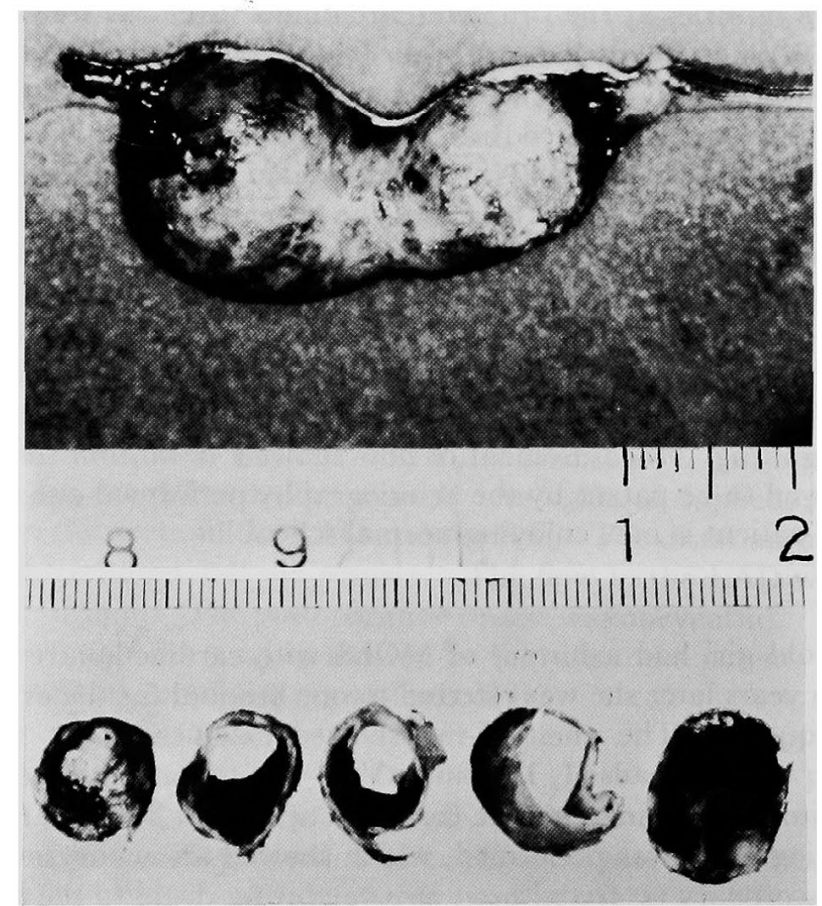

Fig. 2. The excised aneurysms in Case 4 (top) and its cross-sections at various levels (bottom). 


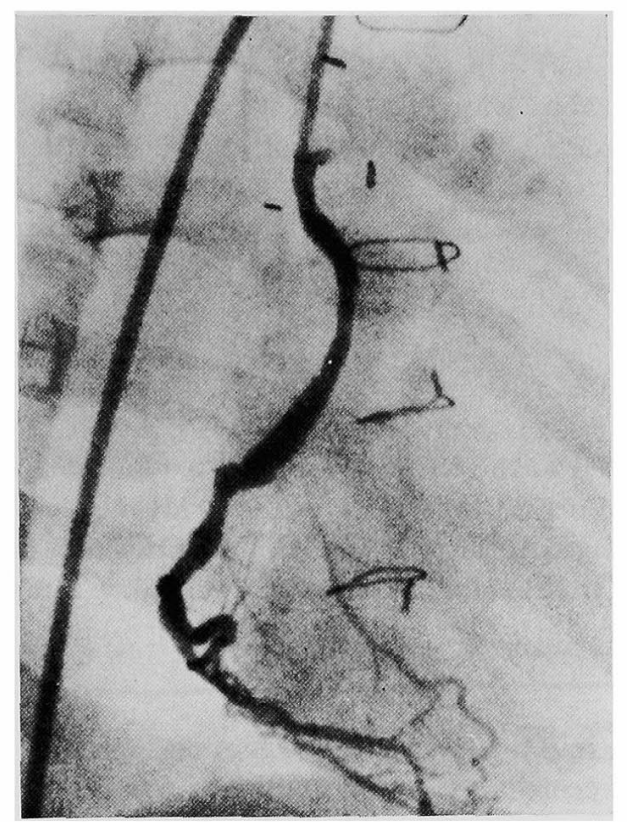

Fig. 3. The postoperative angiogram in Case 4 shows a patent graft to the right coronary artery.

operation was performed on January 27, 1978. The operative procedures consisted of anastomosis of the autogenous saphenous venous graft to the $\mathrm{RC}$ with interrupted 6-0 silk sutures and the excision of the aneurysms of the right coronary artery. Flow through the graft was $45 \mathrm{ml} / \mathrm{min}$. Excised aneurysms in series sized $3.0 \times 1.5 \mathrm{~cm}$, the wall of which was calcified. Organized thrombus was found in the aneurysms. The postoperative course was uneventful. Patency of the graft was shown by angiography performed 1 month after the surgery. She is now enjoying normal school life.

\section{Case 5}

A 7-year-old boy developed MCLS at the age of 2 months. Seven months later he suddenly developed cyanosis and vomiting. ECG was interpreted as anterior myocardial infarction. Aortogram showed the right coronary artery to be the site of multiple aneurysms, the anterior descending artery to be occluded and the circumflex to be patent. Two years later he was referred to our hospital. A selective coronary arteriogram showed $75 \%$ stenosis at the orifice of the right coronary artery with multiple aneurysms distally. The findings of the anterior descending and the circumflex artery were the same as those obtained by the previously performed aortography. The ventriculography showed a left ventricular aneurysm.

Operation was performed on April 10, 1978. The procedures consisted of anastomosis of an autogenous saphenous vein graft to the RC with interrupted 6-0 silk sutures and left ventricular aneurysmectomy. The flow of the graft was 43 $\mathrm{ml} / \mathrm{min}$. Convalescence was smooth. The graft was confirmed to be patent by the postoperative angiography performed 1 month after the surgery. He is now in good condition. 
Case 6

A 6-year-old girl had a history of MCLS at the age of 1 year and 10 months. One year later aortography was performed, which revealed aneurysms at the origins of both the left and the right coronary arteries. Thereafter she was treated with a daily administration of warfarin. Selective angiography performed 3 years later showed a calcified aneurysm at the left main trunk with complete occlusion of the LAD and $75 \%$ stenosis at the origin of the CX. The RG was observed to have multiple stenoses ranging from 25 to $50 \%$ in the proximal portion. The LAD was opacified through the collaterals from the RC. Ventriculography showed hypokinetic left anterior wall. ECG showed ST segment depression after exercise.

Operation was performed on December 3, 1979. Autogenous saphenous vein grafts were anastomosed to the LAD and the CX. Blood flow through the graft to the LAD was $18 \mathrm{ml} / \mathrm{min}$ and that to the $\mathrm{CX} 60 \mathrm{ml} / \mathrm{min}$. Convalescence was uneventful. Selective angiography performed 1 month later showed the graft to the CX to be patent, but that to the LAD to be occluded. The patient is now leading normal school life.

\section{Case 7}

A 5-year-old boy had a history of MCLS at the age of 1 . One month later he suddenly developed precordial pain and vomiting. Abnormality of coronary artery system was shown by angiography. Thereafter he was treated with a daily administration of aspirin. Three years later he was admitted for re-examination. ECG showed incomplete right bundle branch block but no abnormality of ST segments and $\mathrm{T}$ waves. However frequent supraventricular extrasystoles were observed after exercise. Selective coronary angiography showed $75 \%$ stenosis at the origin of the $\mathrm{LAD}$ and multiple stenoses ranging from 50 to $60 \%$ at the proximal RC.

Operation was performed on February 4, 1980. Autogenous saphenous vein grafts were anastomosed to the LAD and the RG. Blood flow through the graft to the $\mathrm{LAD}$ was $50 \mathrm{ml} / \mathrm{min}$, and that to the $\mathrm{RC} 40 \mathrm{ml} / \mathrm{min}$. Postoperative course

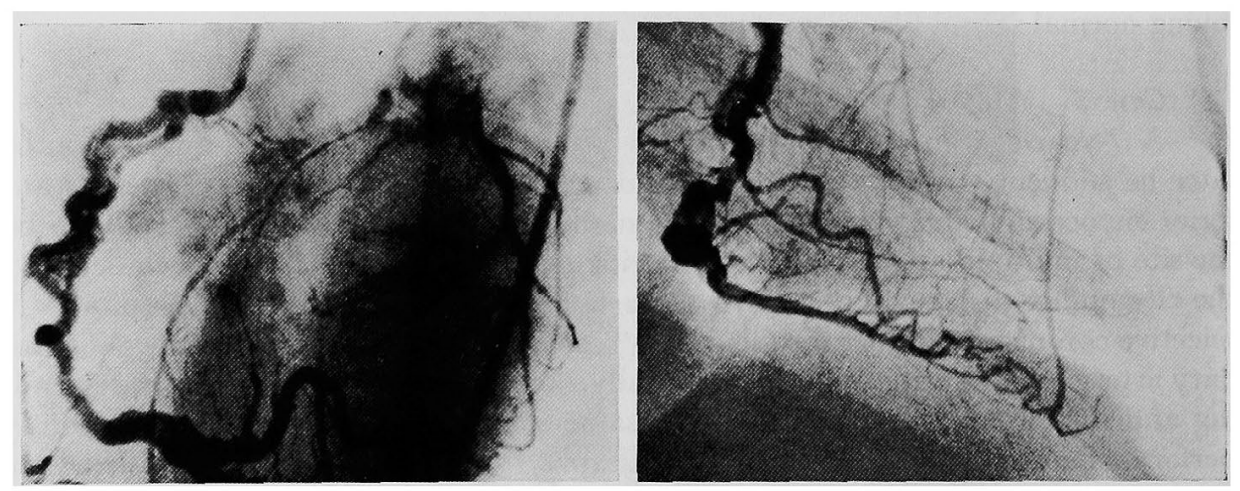

Fig. 4. The preoperative right coronary angiograms in Case 8 show multiple stenoses extending from the proximal to the middle portion of the right coronary artery. The left anterior descending artery and the circumflex artery are retrogradely opacified. A calcified aneurysm at the left main trunk is also visible on the left side of the LAO projection. Left: LAO, right: RAO. 

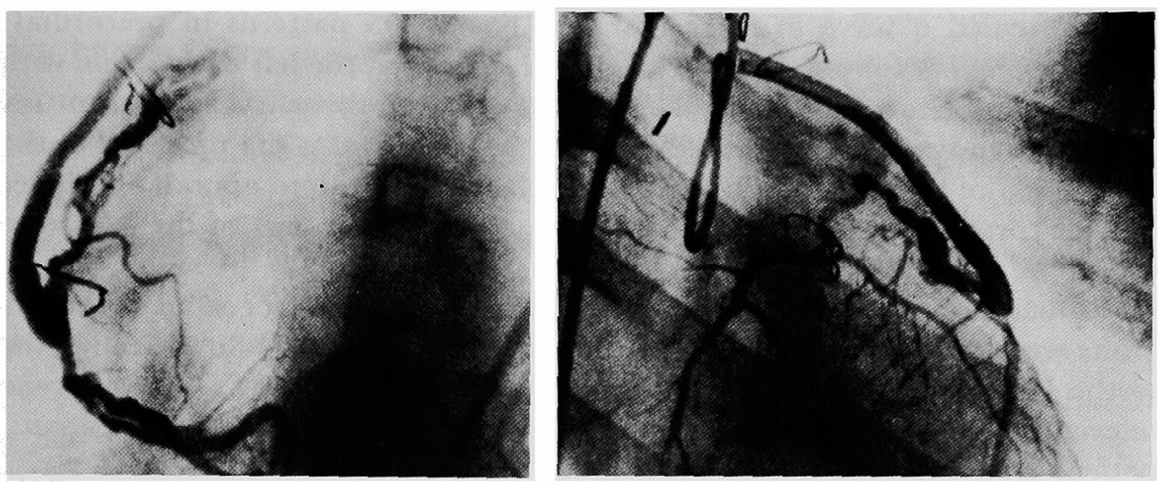

Fig. 5. The patency of the grafts to the right coronary artery (left) and the anterior descending artery (right) in Case 8 is shown by the postoperative angiograms.

Table I. Surgical Procedures and Postoperative Status

\begin{tabular}{|c|c|c|c|c|}
\hline Case & $\begin{array}{l}\text { Age } \\
\text { Sex } \\
(y r s)\end{array}$ & Surgical procedures & $\begin{array}{l}\text { Postoperative* } \\
\text { graft patency }\end{array}$ & Early result \\
\hline 1 & $\begin{array}{c}7 \\
\mathrm{~m}\end{array}$ & $\begin{array}{l}\text { LAD grafting } \\
\text { RC grafting }\end{array}$ & $\begin{array}{l}\text { patent } \\
\text { patent }\end{array}$ & $\begin{array}{l}\text { increased } \\
\text { exercise tolerance }\end{array}$ \\
\hline $2^{* *}$ & $\begin{array}{l}9 \\
f\end{array}$ & $\begin{array}{l}\text { CX grafting } \\
\text { RC grafting }\end{array}$ & $\begin{array}{l}\text { occluded } \\
\text { patent }\end{array}$ & $\begin{array}{l}\text { no anginal } \\
\text { attack }\end{array}$ \\
\hline 3 & $\begin{array}{r}9 \\
\mathrm{~m}\end{array}$ & LAD grafting & patent & no symptom \\
\hline 4 & $\begin{array}{l}6 \\
f\end{array}$ & $\begin{array}{l}\text { Right coronary aneurysmectomy } \\
\text { RC grafting }\end{array}$ & patent & no symptom \\
\hline 5 & $\begin{array}{c}7 \\
\mathrm{~m}\end{array}$ & $\begin{array}{l}\text { RG grafting } \\
\text { Left ventricular aneurysmectomy }\end{array}$ & patent & $\begin{array}{l}\text { increased } \\
\text { exercise tolerance }\end{array}$ \\
\hline 6 & $\begin{array}{l}6 \\
f\end{array}$ & $\begin{array}{l}\text { LAD grafting } \\
\text { CX grafting }\end{array}$ & $\begin{array}{l}\text { occluded } \\
\text { patent }\end{array}$ & no symptom \\
\hline 7 & $\begin{array}{r}5 \\
\mathrm{~m}\end{array}$ & $\begin{array}{l}\text { LAD grafting } \\
\text { RC grafting }\end{array}$ & $\begin{array}{l}\text { patent } \\
\text { patent }\end{array}$ & no symptom \\
\hline 8 & $\begin{array}{l}13 \\
\mathrm{~m}\end{array}$ & $\begin{array}{l}\text { LAD grafting } \\
\text { RC grafting }\end{array}$ & $\begin{array}{l}\text { patent } \\
\text { patent }\end{array}$ & $\begin{array}{l}\text { no anginal } \\
\text { attack }\end{array}$ \\
\hline
\end{tabular}

* One month after the surgery, ** The patient died suddenly 3 years after the surgery.

was uneventful. The patency of both the grafts was confirmed by angiography performed 1 month after the operation.

Case 8

A 13-year-old boy had a history of MCLS at the age of 5. Thereafter he was free of any symptom until 8 years later, when he suddenly developed anginal pain. 
ECG revealed $q$ wave in leads $I$ and aVF and QS patterns in precordial leads. Selective angiography showed a calcified aneurysm at the left main trunk with complete occlusion of the LAD and the CX. Right coronary angiogram revealed multiple stenoses ranging from 25 to $70 \%$ extending from the proximal to the middle portion of the RC, and branching off the distal RG into abundant collaterals to the left coronary arteries. Ventriculography showed a part of the left ventricular wall to be akinetic.

Operation was performed on February 1, 1980. Autogenous saphenous vein grafts were anastomosed to the LAD and to the RC. Blood flow through the graft to the $\mathrm{LAD}$ was $100 \mathrm{ml} / \mathrm{min}$ and that to the $\mathrm{RC} 120 \mathrm{ml} / \mathrm{min}$. Convalescence was uneventful. Postoperative angiogram showed both the grafts to be patent. The patient is now leading normal school life.

\section{Discussion}

In 1970 the Research Committee for MCLS, supported by the Ministry of Health and Welfare of the Japanese Government, was organized to elucidate the clinical, pathological, epidemiological, and etiological features of the disease. The national survey carried out by the Committee in 1978 showed the total number of the patients with a history of MCLS to be 18182.9" During the 2 years ('76-'78) the mortality rate was $0.5 \%$, while it accounted $1-2 \%$ before 1976. Eighty-five $\%$ of the patients were infants and young children under 5 years of age, the males being affected one and a half times more frequently than the females. ${ }^{3}$ )

In MCLS necrotizing panarteritis has been frequently observed in the middle sized arteries such as the coronary arteries. ${ }^{10), 11)}$ During the inflammatory phase and the healing process, various morphological changes take place in the coronary arterial system, sometimes leading to myocardial ischemia, myocardial infarction, and papillary muscle dysfunction. The morphological changes of the coronary artery system are characterized by frequent multiple saccular or fusiform aneurysm formation in addition to stenosis. It is reported that aneurysm was found in about $20 \%$ of the cases examined by angiography. ${ }^{121}$ Seventy-four \% of aneurysms were found at the origin of the bifurcation of the left coronary artery into the LAD and the $\mathrm{CX}$ and $48 \%$ at the origin of the right coronary artery. Most of the remaining aneurysms were found at the more distal bifurcations of the coronary arteries. As for the shape of aneurysm, $74 \%$ were of saccular type while $30 \%$ were of fusiform type. The favorite site of aneurysms was the same as that of the atherosclerotic changes in adult patients. Greater mechanical force, such as shear stress exerted at the origin and bifurcation of vascular tree might potentiate aneurysmal formations of the inflammatory vascular walls in the same manner as inducing atheromatous changes in the adults. 
The surgical treatments reported so far are Vineberg procedure, ${ }^{13)}$ aortocoronary bypass using autogenous or homologous saphenous vein graft, aneurysmectomy with aortocoronary bypass, ventricular aneurysmectomy and mitral valve replacements. ${ }^{14}$ ) As the etiology and the natural course of MCLS are not known, the surgical indication has been controversial. At present, we have selected patients for A.C bypass, where more than one major coronary arteries have been observed to be significantly narrowed. However, special attention should be paid in the surgery of MCLS, because the coronary artery lesions differ from those of atherosclerotic lesions in the adults in that in the former multiple aneurysms are frequently observed in a beads-like shape.

Our previous experiments using bead-shaped model simulating aneurysm indicated that considering the pressure drops 1 bead, 2 and 3 beads in series had stenosing effects equivalent to that of a $50 \%$, a $55 \%$, and a $70 \%$ orifice narrowing respectively in the range of Reynolds number between 200 and $1,500 .{ }^{17)}$ In addition to aneurysmal formation, multiple stenoses, and tortuosity are usually found in the coronary arteries. It is reported that multiple non-critial stenoses also cause a significant stenosing effect. ${ }^{18}$ Therefore, both the aneurysms and the stenoses should be taken into account for assessing the total stenosing effect in the coronary lesions.

Another problem associated with aneurysm is thrombus formation inside the aneurysm. Amano and his coworkers ${ }^{19}$ examined the coronary artery system in 37 autopsied cases, in which aneurysm was usually accompanied by thrombosis. Selective angiograms performed by us clearly showed the turbulence, swirling, and stagnation of blood flow in the aneurysms, indicating high possibility of thrombus formation and peripheral embolization. In the acute phase of MCLS, thrombocytosis has been observed, ${ }^{20)}$ which might accelerate thrombogenesis at the damaged vascular wall of the ancurysm. Although the resected aneurysms herein reported had an orgainzed thrombus, the turbulence and stagnation of flow might induce fresh thrombus formation and embolization. In such cases, the resection of aneurysm or obliteration of the outlet artery combined with A-G bypass might be justified.

The surgical techniques are not different from those employed in A-C bypass in the coronary artery disease in the adults. The saphenous vein of the patients over 6 years of age were 2 to $3 \mathrm{~mm}$ in diameter and found of adequate size for grafting. The coronary arteries to be grafted were usually more than $1.0 \mathrm{~mm}$ in diameter. An interrupted $7-0$ silk suture was used for the distal anastomosis in the smaller arteries, while an interrupted 6-0 silk sutures was employed for the anastomosis in the larger arteries. The patency rate of $85 \%$ observed 1 month after the surgery might be acceptable.

There are several points to be considered about the aortocoronary bypass 


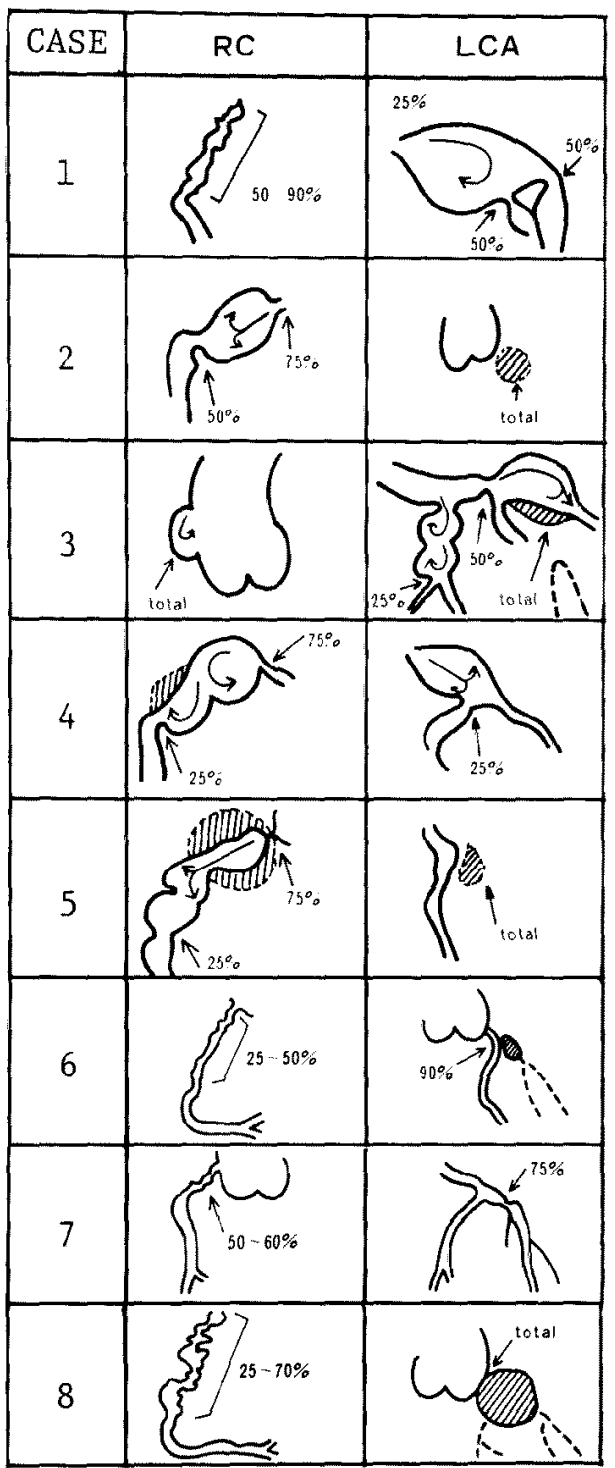

Fig. 6. The illustrative schema of the preoperative angiographic findings of the coronary arteries. The degree of stenosis is indicated in percentage. Total means total obstruction. The dotted lines indicate the coronary arteries opacified via collaterals. The shaded areas indicate the possibility of thrombus formation in the aneurysms (thrombus was confirmed at the time of surgery in Case 4). The curved lines indicate turbulent flow observed in cineangiograms.

in the patients with Kawasaki disease. First of all, it is not known how long a saphenous vein graft continues to function, and whether the size of anastomosis would enlarge and the length of the graft become longer with the growth 
of the patient. Although satisfactory long-term results have been obtained in the aortocoronary bypass in the adult patients of atherosclerotic coronary disease, there is a report indicating that bypass operation for anomalous origin of the left coronary artery in children has high incidences of graft failure. ${ }^{211}$ In some of the patients younger than 4 years, autogenous saphenous vein being too small, saphenous veins taken from the mother had been reported to be employed. ${ }^{151,22)}$ However, the long-term patency of the homologous graft is questionable. Until the fate of grafts is elucidated by future research, it might be recommended in the light of the above considerations to put off the operation as late as possible.

Secondly, it had been reported that in autopsied cases the inflammatory changes were observed not only in the arteries, but also in the veins, such as the coronary vein, vena cava inferior, vena portae or mesenteric vein. ${ }^{19), 23}$ Although no description was given about saphenous vein, the vein is probably not immune to such inflammatory changes. It is the point to be considered whether the graft can tolerate arterial blood pressure when phlebosclerotic changes exist in the vein used as a graft, although macroscopic changes have not been observed by us.

Thirdly, although coronary aneurysm was usual finding in the succumbed, and frequent finding in the survivors, there is a report of a tendency for regression of coronary artery disease in certain cases evidenced by serial angiographic studies. ${ }^{24}$ Natural regression observed by angiography has been reported to take place usually within 1 or 2 years after the onset of the illness and might be due to the smoothing of the arterial wall by intimal proliferation of the aneurysm and recanalization of thrombosed arteries, however long persisting changes of arteries might hardly regress. In case of aortocoronary bypass performed within the period of regression, probability of graft failure might be higher due to increase of flow through the regressed coronary arteries. Since the course of coronary arterial changes is as yet not fully understood, close examination of the patency of grafts as well as the diseased coronary arteries must be imperative.

\section{REFERENGES}

1. Kawasaki T: Acute febrile mucocutaneous syndrome with lymphoid involvement with specific desquamation of the fingers and toes in children-clinical observations in 50 cases. Jap J Allerg 16: 178, 1967 (in Japanese)

2. Yanagawa H: Epidemiology of Kawasaki disease. Jap J Clin Med 34: 275, 1976 (in Japanese)

3. Kawasaki T, Kosaki F, Okawa S, Shigematsu I, Yamagawa H: A new infantile acute febrile mucocutaneous lymph node syndrome (MLNS) prevailing in Japan. Pediatrics 54:271, 1974

4. Asai T, Kusakawa S: Coronary angiography in mucocutaneous lymph node syndrome. 
Jap Med J 2594: 37, 1974 (in Japanese)

5. Kitamura S, Kawashima $Y$, Miyamoto K, Kobayashi $T$, Matsuda H, Ohgitani N, Kodama K, Minamino T, Manabe $\mathrm{H}$ : Multiple coronary artery aneurysms resulting in myocardial infarction in a young man; Treatment by double aorto-coronary saphenous vein bypass grafting. J Thorac Cardiovasc Surg 70: 290, 1975

6. Kitamura S, Kawashima Y, Fujita T, Mori T, Oyama C, Fujino M, Kozuka T, Nishizaki K, Manabe $\mathrm{H}$ : Aortocoronary bypass grafting in a child with coronary artery obstruction due to mucocutaneous lymphnode syndrome. Report of a case. Circulation 53: 1035, 1976

7. Takeuchi $Y$, Suma K, Shiroma K, Tsuji T, Inoue K, Koyama Y, Tokuchi K, Yoshikawa T, Asai T, Kusakawa S, Nakajima K: Coronary artery changes in Kawasaki diseases and its surgical treatment by aorto-coronary bypass grafting. Jap Thorac Surg 31: 356, 1978 (in Japanese with English abstract)

8. Suma K, Takeuchi Y, Tsuji T, Shiroma K, Inoue K, Yoshikawa T, Koyama Y, Tokuchi K, Narumi J, Ochi M, Nakajima K, Asai T, Kusakawa S: The experience of surgical treatments of five children with Kawasaki disease (Mucocutaneous Lymph Node Syndrome). With special reference to the surgical indication of the coronary arterial lesions. Jap J Assoc Thorac Surg 27: 1564, 1969 (in Japanese with English abstr)

9. Kusakawa S: Personal communication, 1980

10. Tanaka $M$, Sekimoto $K$, Naoe $\mathbf{E}$ : Kawasaki disease, relationship with infantile periarteritis nodosa. Arch Pathol Lab Med 100: 81, 1976

11. Fujiwara H, Hamashima $\mathrm{X}$ : Pathology of the heart in Kawasaki disease. Pediatrics 61: 100,1978

12. Ishihara J, Asai $\mathrm{T}$ : Radiological findings of Kawasaki disease. Jap J Clin Radiol 23: 913, 1978 (in Japanese with English abstr)

13. Yamaguchi S: Personal communication, 1973

14. Konishi Y, Tatsuta N, Miki S, Chiba Y, Kao C, Hikasa Y, Yokota M, Nishioka K, Ueda T, Kamiya T, Sugiyama $T$ : Mitral insufficiency secondary to mucocutaneous lymph node syndrome. A case report of successful surgical treatment. Jpn Circulat J 42: 901, 1978

15. Konishi $Y$, Tatsuta N, Miki S, Matsuda M, Ishihara H, Taniguchi $T$, Hikawa $Y$, Hayashidera $T$, Nishioka K, Ueda $T$ : Simultaneous surgical treatment of tretralogy of Fallot and coronary artery aneurysm due to mucocutaneous lymph node syndrome in a 4-year-old child. Jpn Circulat J 43: 749, 1979

16. Sandiford FM, Vargo TA, Shih JY, Pelargonio S, McNamara DG: Successful triple coronary artery bypass in a child with multiple coronary aneurysms due to Kawasaki's disease. J Thorac Cardiovasc Surg 79: 283, 1980

17. Yoshikawa T, Suma K, Sugawara M: Hemodynamic effects of beads-shape aneurysm in Kawasaki disease. Respiration and Circulation 28: 395, 1920 (in Japanese with English abstract)

18. Karayannacos PE, Talukder N, Nerem RM, Roshon S, Vasko JS: The role of multiple noncritical arterial stenoses in the pathogenesis of ischemia. J Thorac Cardiovasc Surg 73: 458, 1977

19. Amano S, Hazama F, Hamashima $Y$; Pathology of Kawasaki disease: I Pathology and morphogenesis of the vascular changes. Jpn Circulat $J$ 43: 633, 1979

20. Wada E: Hematological findings of MCLS. in Research Progress of Kawasaki Disease, ed by Kawasaki T, Kusakawa S, Shigematsu I, Kindai Shuppan, Tokyo, p. 134, 1976 (in Japanese)

21. Ebert PA, Peter RH, Gunnels JG, Sabiston DC: Resecting and grafting of coronary artery aneurysms. Circulation 43: 593, 1971

22. Wada J: Personal communication, 1978

23. Amano S, Hazama F, Hamashima Y: Pathology of Kawasaki disease: II. Distribution and incidence of the vascular lesions. Jpn Circulat J 43: 741, 1979

24. Kato H, Koike S, Yamamoto M, Ito Y, Yano E: Coronary aneurysms in infants and young children with acute febrile mucocutaneous lymph node syndrome. J Pediatrics 86: 892, 1975 